\title{
Produto educacional sobre educação algébrica escolar: pensamento algébrico, linguagem, generalização
}

School algebraic education: algebraic thinking, language,generalizing process

\author{
Juliano Pereira da Silva ${ }^{1}$ \\ Plinio Cavalcanti Moreira²
}

\begin{abstract}
Resumo
Neste texto, discutimos algumas das principais questões relativas ao ensino e à aprendizagem da álgebra na escola básica, de acordo com a literatura especializada.O Produto Educacional aqui apresentado pode ser utilizado como material complementar tanto no processo de formação do professor de matemática na licenciatura,comona prática docente escolar, pelos professores já em exercício. O objetivo é oferecer ao professor ou futuro professor uma discussão teórica a respeito dequestões diretamente relacionadas ao ensino e aprendizagemda álgebra escolar e, ao mesmo tempo, sugestões de atividades já testadas em sala de aula, visando a construção, por parte do interessado, de um conjunto de conhecimentos relevantes para a prática docente na escola básica, mais especificamente, no trabalho de educação algébrica.
\end{abstract}

Palavras-chave: Educação matemática. Educação algébrica escolar. Ensino e aprendizagem matemática. Linguagem algébrica. Pensamento algébrico.

\begin{abstract}
We discuss some important issues related to the teaching and learning of algebra at school, according to the specialized literature.The so called Educational Product we present here may serve as complementary material either in mathematics teacher education programs or in effective teaching practice at school. The goal is to offer both to the prospective and in service teacher a theoretical frame for dealing with some issues directly related to the process of algebraic education at school, together with tasks already validated through research-designed intervention, so that the prospective and/or in service teacher may have, at her/his disposal, a set of knowledge readily useful in her/his professional practice of algebraic education of youngsters.
\end{abstract}

Keywords: Mathematics education. School algebraic education. Mathematics teaching and learning. Algebraic language. Algebraic thinking.

\footnotetext{
${ }^{1}$ Mestre em Educação Matemática, Professor EBTT, IFMG/Campus Ouro Preto, juliano.silva@ifmg.edu.br

2Doutor em Educação, Professor Adjunto, Departamento de Educação Matemática/UFOP, pliniocavalcantim@gmail.com
} 


\section{Introdução: origem, características e contribuições deste produto educacional para a prática docente escolar e de formação}

A pesquisa que deu origem a esteProduto Educacional tratou de responder às seguintes perguntas de investigação:

a) Quais são os conhecimentos matemáticos sobre álgebra trabalhados nas disciplinas obrigatórias do currículo do curso de Licenciatura em Matemática da Universidade Federal de Minas Gerais?

b) Como esses conhecimentos (identificados na Questão a) se relacionam com as demandas de conhecimento da prática docente em matemática na Educação Básica?

No decorrer do estudo da literatura especializada, com o objetivo de produzir respostas para essas questões de pesquisa, entramos em contato com um material riquíssimo, que aponta dificuldades enfrentadas pelos alunos ao longo da educação algébrica escolar, textosque abordam didaticamentealguns tópicos importantes da álgebra da escola básica, assim como propostas de atividades, apoiadas em estudos científicos, para o trabalho docente de oferecer ao aluno a oportunidade de desenvolvimento da capacidade de superação dessas dificuldades. A partir deste levantamento, construímos o Produto Educacional aqui apresentado, que se destina a professores (ou futuros professores) da Educação Básica, bem como a formadores que atuam em licenciaturas em matemática. $\mathrm{O}$ conhecimento matemático relevante para o trabalho de educação algébrica escolar, identificado a partir da literatura analisada, compõe um amplo espectro, mas por uma questão de espaço, abordaremos aqui apenas algumas das questões e das propostas que consideramos mais relevantes na formação do professor (ver seção 2 adiante).

Achamos importante reunir neste Produto Educacionalalgumas dessas questões e propostasporque um problema frequentemente apontado em relação aos processos de divulgação da pesquisa científica no campo da Educação Matemática é a dificuldade de acessoà literatura especializada, por parte do 
professor (ou do futuro professor) da escola básica. No caso do Brasil, vários fatores podem estar relacionados a essa dificuldade. Entre eles, citamos dois especialmente impactantes e interligados: a) a escassez de publicações dirigidas diretamente aos professores de matemática da escola básica, em que sejam tratados temas específicos da matemática escolar, numa perspectiva que contemple de modo abrangente os resultados das pesquisas relacionadas com 0 tema; b)o fato de que boa parte desse tipo de literatura científica encontra-se, muito frequentemente, em língua estrangeira.Outro fator decisivo se refere à tendência da produção científica atual no campo da Educação Matemática (bem como em vários outros), em que as investigações são cada vez mais centradas em questões muito específicas, de tal modo que a utilização de seus resultados em sala de aula da escola básica, no trabalho com um tema mais abrangente como, por exemplo, educação algébrica - demandaria uma avaliação, síntese e eventual integração de informações provenientes de uma quantidade muito grande de pesquisas primárias. Meta-análises de pesquisas requerem formação especializada, experiência e familiaridade com as diferentes questões abordadas e com as diferentes perspectivas teórico-metodológicas utilizadas em cada uma das pesquisas a serem analisadas. E, de modo geral, o professor da escola básica não tem nem formação adequada para esse trabalho, nem tempo para executá-lo.

Assim, este texto visatrazer contribuições concretas tanto para a prática do professor de matemática, no que se refere ao trabalho com a álgebra na escola básica, comotambém para a do formador de professores, nas licenciaturas em matemática, ajudando a preencher algumas das lacunas comentadas acima.Alertamos, entretanto, que não estamos oferecendo um receituário para o ensino de álgebra na escola, até porque sabemos que cada sala de aula, em cada escola, tem suas especificidades e peculiaridades, de modo que conhecimentos sobre a álgebra escolar que foram frutíferos em determinado contexto de ensinopodem não o ser em outro. Aliás, isso parece estar na raizda complexidade do conhecimento matemático para o ensino escolar. 
Assim, nosso objetivo, como já frisamos, é oferecer, num único texto, exemplos de questões teóricas e de atividades ou tarefas, já testadas positivamente no contexto escolar, as quais podem servir de inspiração para o professor no planejamento e execução de suas próprias aulas. Este texto também pode servir como material complementar ao trabalho de formação do professor nas licenciaturas em matemática. É claro que o professor (ou o formador de professores) deverá, em cada caso,examinar criticamente, experimentar, filtrar, adaptar e/oureformular as abordagens aqui propostas. O importante é que ocorra uma problematizaçãoda prática docente escolara partir das ideias aqui discutidas, as quais têm como base geral pesquisas já desenvolvidas e validadas sobre o ensino e a aprendizagem da álgebra na escola. Assim, este trabalho pretende oferecer diretamente ao professor (e ao formador de professores) um extrato (restrito, dado o espaço com que se pode contar em publicações em periódicos) de resultados de pesquisas que podem servir de base para reflexão ao preparar suas aulas,além de propor alternativas de abordagem para algumas das questões fundamentais da educação algébrica escolar.

As limitações do texto vão se referir, por um lado, a esse espaço restrito mencionado acima e, por outro, à eventual transposição do contexto particularem que as intervenções aqui descritas foram realizadas para cada um dos contextos particulares em que trabalhe o leitor interessado em levar essas ideias para a sua prática docente.As experiências que deram origem às conclusões e observações que sintetizamos neste trabalho foram vivenciadas $e$ analisadas por pesquisadores que tiveram(a seu modo) uma formação profissional; que conheciam(a seu modo) a literatura associada às questões da educação algébrica envolvidas nas atividades trabalhadas nesses testes etc. Ao serem transpostas para a prática de outros professores, com outra formação, em outro contexto de organização e de cultura (escolar ou de formação), essas experiências se tornam "novas", exigindo todo um processo de filtragem e adaptação às (também novas) condições em que venham a ser utilizadas. Isso pode funcionar positivamente como um desafio, mas não deixa de ser uma limitação do texto, no sentido de que 
não propomos (nem estava em nossos propósitos) sugestões para possíveis formas de filtragem e adaptação, a cada contexto específico, das ideias que aqui discutimos. Por outro lado, confiamos que cada professor ou formador suficientemente interessado, possa vivenciar a experiência de utilização deste texto em sua prática docente e, eventualmente, oferecer contribuições a seus pares e a nós, os autores.

\section{Questões teóricas e atividades práticas}

\subsection{A letra como número}

Kuchemann (1981) estabelece seis situações matemáticas em que as letras desempenham papéis diferentes, substituindo números. Comentamos, aqui, apenas três destespapéis, aqueles que consideramosmais diretamente vinculados às situações comuns da prática de ensino escolar:

1. A letra assume o papel de uma incógnita, ou seja, um valor desconhecido, mas determinado, fixo, a ser encontrado. Exemplo: achar o valor de $x$ que satisfaz a igualdade $x^{2}+3 x+4=0$. Situações como essa demandam habilidade de manipulação algébrica envolvendo uma diversidade de operações com a letra, como se ela fosse um número conhecido.

2. A letra é vista como um representante genérico dos elementos de um dado conjunto, podendo então, assumir diversos valores pré-fixados. Exemplo: na identidade $(x+1)^{2}=x^{2}+2 x+1$, não se trata de nomear por $x$ um valor desconhecido que precisa ser determinado, mas de dizer que a igualdade é válida qualquer que seja o valor que $x$ assuma.

3. A letra é entendida como uma variável num sentido funcional, isto é, a letra percorre diferentes valores dentro de um determinado domínio numérico, provocando, desta forma, variações nos valores de uma expressão algébrica que depende dela. Exemplo de uma tarefa em que a letra tem esse papel: sendo $n$ um número natural, qual é maior, $2 n$ ou $n+2$ ?

É importante que o professor entenda essas diferenças,pois não é fácil ao aluno explicitar suas dificuldades em relação a esse aspecto, cabendo ao professor percebê-las, sem contar com uma pergunta direta do aluno. 


\subsection{0 desenvolvimento do pensamento algébrico}

Segundo Ponte, Branco e Matos (2009), pode-se identificar uma tendência, no campo da Educação Matemática,no sentido de recomendar que o desenvolvimento do pensamento algébrico seja estimulado desde os primeiros ciclos dos anos iniciais, como preparação para as aprendizagens escolares posteriores. Mas o que significa desenvolver o pensamento algébrico?O desenvolvimento do pensamento algébrico pode ser entendido, essencialmente, como odesenvolvimento da capacidade deproduzir generalizações em matemática. Pensar algebricamente significa saber lidar com valores indeterminados e saber generalizar.Todas as crianças, em qualquer idade, podem aprender a pensar algebricamente, de acordo com seu estágio de desenvolvimento cognitivo. Para expressar as generalizações, quando solicitadas, as criançaslançam mão de vários recursos, ainda nas séries iniciais. Fazem uso de desenhos, gestos, palavras, entre outras formasque vão se aprimorando ao longo dos anos de escolaridade, chegando, eventualmente, à utilização de letras em lugar de números, como na linguagem algébrica padronizada. $O$ pensamento algébrico começa a se desenvolver antesdo domínio da linguagem algébrica padrão, ou seja, esta última não é condição para o desenvolvimento do pensamento algébrico, embora constitua uma alavanca poderosa, a partir de certo momento.Assim, estudiosos defendem que o foco do desenvolvimento do pensamento algébrico não deve ser posto, num primeiro momento, no uso das letras, mas na compreensão das relações existentes entre objetos importantes em uma dada situação (Radford, 2011).

Os estudos e pesquisas mais atuais sugerem uma abordagem escolar da álgebra voltada inicialmente para a formação e o desenvolvimento do pensamento algébrico, passando por vários níveis e formas de expressão das generalizações pensadas e culminando, eventualmente, com a apropriação da linguagem algébrica padrão. Sugere-se que as crianças dos anos iniciais da escola sejam incentivadas, através, por exemplo, do uso de sequências numéricas ou 
pictóricas, a procurar e expressarregularidades e padrões de formação dessas sequências. Os alunos seriam estimulados, num primeiro momento, a usar a linguagem natural, desenhos, gestos, palavras ou quaisquer outras formas de expressão a seu alcance. Ao longo do processo escolar, o uso das sequências para o reconhecimento de padrões, assim como outras formas de lidar com a ideia de quantidades variáveis ou indeterminadas, deve prosseguir e se aprofundar, no sentido de um amadurecimento gradativo do pensamento algébrico. Assim, alunos do quinto e sexto anos, por exemplo, trabalhando em atividades didáticas apropriadas, seriam levados a encontrarformas cada vez mais compactas euniversais de expressar suas ideias ligadas à generalização, até que alcancemum grau de abstração compatível com o uso recorrente da simbologia algébrica padronizada.

É preciso, de acordo comPonte, Branco e Matos (2009), que o aluno observe sequências formadas por desenhos, palavras, números, símbolos em gerale faça atividades de reconhecimento dos padrões. Alguns exemplos seriam: continuar uma dada sequência, representando os termos seguintes aos termos fornecidos; descrever a relação entre cada termo e a sua ordem na sequência; usar a relação entre o termo e a sua ordem na sequência para identificaraqueleque ocupa uma posiçãodada e vice-versa(achar a posição - ou possíveis posições -que um dado termo ocupa na sequência); por fim, expressar a relação entre um termo qualquer e sua posição na sequência, em linguagem natural e, dependendo do estágio de aprendizagem, usando a simbologia matemática.

Ponte, Branco e Matosrecomendam o trabalho com, pelo menos, os seguintes tipos de sequências:

1.Sequências "repetitivas": podem ser desenvolvidas em diferentes estágios do processo de escolarização, de acordo com o grau de desenvolvimento cognitivo dos alunos. As tarefas com esse tipo de sequênciadevem propor ao aluno um esforço de percepção do elemento (ou conjunto de elementos) que se repete, a identificação do próximo termo da sequência, a indicaçãodos termos não 
fornecidos da sequência, de acordo com sua posição etc.. Exemplos de atributos que distinguem o conjunto que se repete:

(i) o tamanho

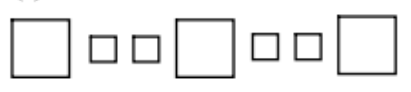

(ii) a cor

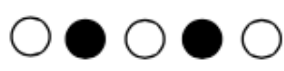

(iii) a orientação

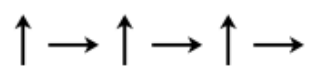

Figura I. Atributos de conjuntos repetitivos. Ponte, Branco e Matos, 2009, p.48

As sequências repetitivas podem ser utilizadas, posteriormente na aprendizagem matemática mais formalizada (no nível apropriado de formalização, é claro).Por exemplo, no estudo da divisibilidade entre números naturais, pode-se utilizara sequência:

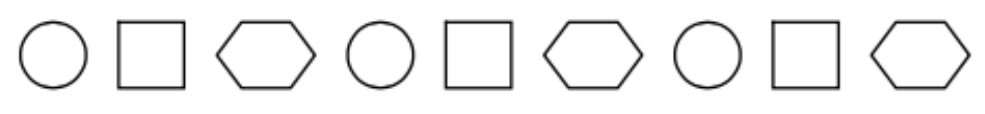

Figura II. Sequências com elementos geométricos. Ponte, Branco e Matos, 2009, p.50

Relacionando cada polígono com sua posição, podemos associar 0 hexágono às posições dadas pelos múltiplos de $3\left(3^{\circ}, 6^{\circ}, 9^{\circ}, \ldots.\right)$. Assim os alunos poderiam reconhecer os elementos da sequência, a partir de sua posição. As perguntas“Qual polígono ocupa a 24a posição? E a 35a?” poderiam ser, então, respondidas em associação com o reconhecimento de 24 como múltiplo de 3 , e de 35 como um múltiplo de 3 mais 2.

2.Sequências "crescentes". O trabalho com esse tipo de sequência visa também o desenvolvimento do senso numérico ("number sense"). Os alunos são levados a produzir generalizações de forma a encontrar uma lei de formação para a sequência e, de acordo com a lei de formação encontrada, identificar termos da sequência, em função da sua posição.Podemos, por exemplo, solicitar aos alunos que descrevam o que acontece na construção de uma tabela,em determinada situação-problema, utilizando a reta numérica para visualização de um padrão:

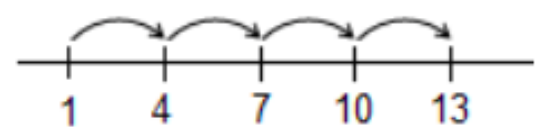

Figura III. Uso da reta numérica nas sequências. Ponte, Branco e Matos, 2009, p.53 issp: 
Podemos também fornecer um termo da sequência e pedir aos alunos que identifiquem a posição (ordem)que esse termo ocupa. Por exemplo, qual é a posição do número 25 na sequência acima? Que número ocuparia a $23^{a}$ posição na sequência?

Para o segundo segmento do Ensino Fundamental, o uso das sequências crescentes também pode levara um aprofundamento da capacidade de produzir generalizações. Seguem alguns exemplos.

2.a) Os alunos podem formar uma visão espacial do que está acontecendo na sequência (ver abaixo). Neste caso, as figuras são construídas a partir da justaposição de cubos e cada imagem se refere a um termo da sequência.
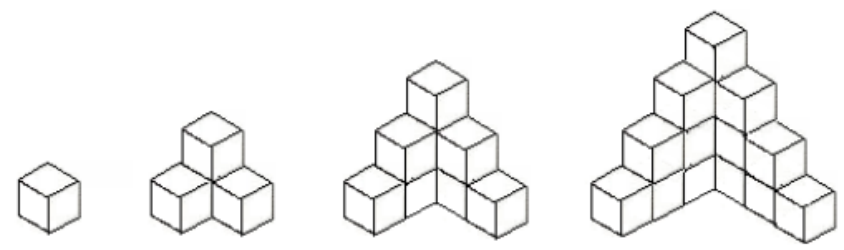

Figura IV. Cubos sobrepostos como sequência. Ponte, Branco e Matos, 2009, p.64 Anecessidade de contagem dos cubos que ficam "escondidos" na figura pode constituir um desafio interessante para alguns alunos, mas também pode oferecer dificuldade para outros. A fim de lidar de modo mais seguro com a situação, o professor pode utilizarcomo recurso um material manipulável, de forma que se viabilize a possibilidade de contar os cubos "manualmente", podendo-seaté avançar na tentativa de formar imagens diferentesdaquelasda sequência originalmente dada, mas com a mesma quantidade de cubos nas posições correspondentes.

2.b)A sequência apresentadalogo adiante é composta por pontos e existe uma relação entre a posição da figura na sequência e o número de pontoscorrespondente. Essa relação pode ser examinada de diferentes perspectivas. Uma possibilidadeé observar que se acrescenta uma linha (diagonal)a cada figura para se obter a próxima. Alternativamente, observa-se que a diagonal tem sempre um ponto a mais que na figura anterior. Sendo $\mathrm{n}$ a posição da figura na sequência, podemos calcular a quantidade de pontos, por exemplo, 
através da associação com um quadrado cujo lado contêm n pontos e que foi dividido ao meio pela sua diagonal (ver o desenho abaixo).

\begin{tabular}{llllllc} 
Ordem & 1 & 2 & 3 & 4 & $\cdots$ & $n$ \\
\hline Número de pontos & 1 & 3 & 6 & 10 & $\cdots$ & $\frac{n(n+1)}{2}$
\end{tabular}

Figura V. Sequência crescente e generalização. Ponte, Branco e Matos, 2009, p.66

3. Sequências puramente numéricas. $O$ exemplo a seguir pode ser uma atividade bastante rica para o desenvolvimento do pensamento algébrico, já que a sequência não vem identificada e há vários tipos de sequência envolvidos em todo o esquema. Os alunos devem identificar uma sequência qualquer e depois encontrar seu termo geral, em função da ordem dos termos.

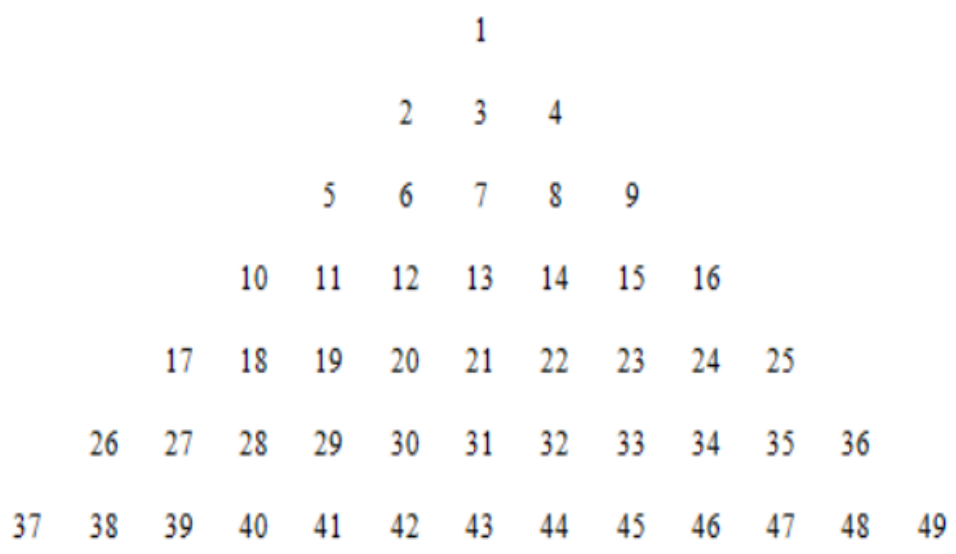

Figura VI. Triângulo numérico. Ponte, Branco e Matos, 2009, p.69

Como sequências a destacar neste esquema, temos, por exemplo, a que constitui o lado mais à direita do triângulo, onde os números são quadrados perfeitos em ordem crescente do topo para a base do triângulo (na próxima figura,esta 
sequência é nomeada sequência $A$ ). Há também sequências recorrentes, onde cada termo é encontrado adicionando-secerto número ao anterior (sequências $B$, $\mathrm{C}$ e $\mathrm{D}$, indicadas na figura seguinte). Esses números adicionados aos termos de cada uma dessas sequênciaspodem formar outra sequência, como, por exemplo,a dos pares a partir de 4 , na sequência $D$ e a dos ímpares, na sequência B.

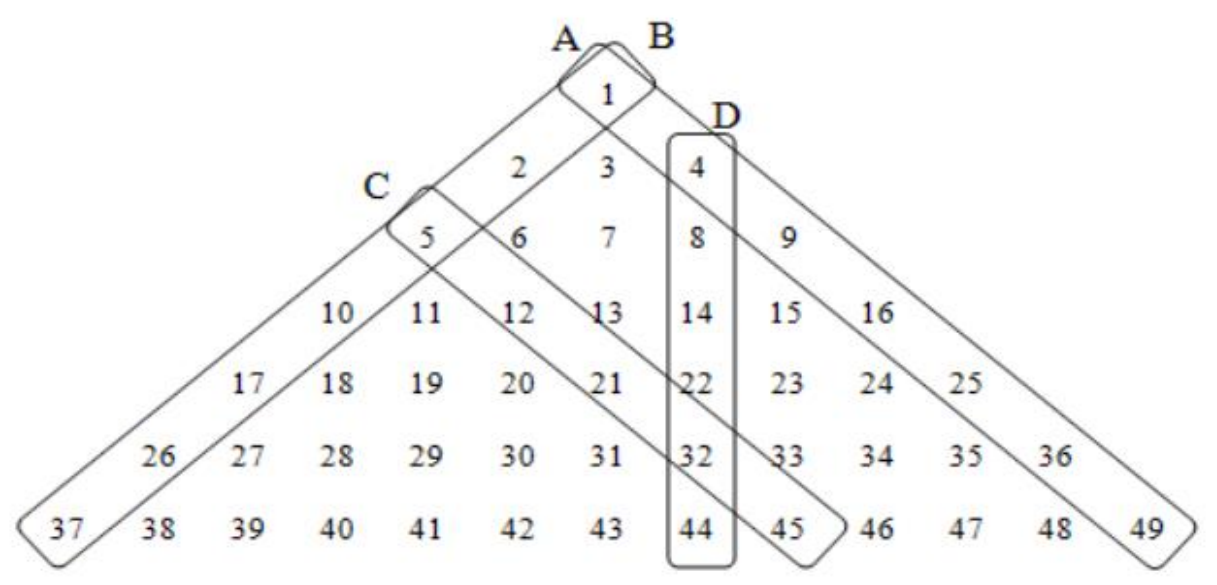

Figura VII. Sequências no triângulo numérico. Ponte, Branco e Matos, 2009, p.70

Nessa atividade, os alunos podem ser solicitados a continuar as sequências que identificarem. Além disto, um esquema próximo a esse, porém mais simples, pode ser utilizado com crianças mais novas, no sentido de desenvolver o pensamento algébrico e o senso numérico.Esse tipo de atividade, trabalhado desde os primeiros ciclos escolares, contribui para a futura consolidação da educação algébrica dos alunos.

O uso de letras para representar variáveis e incógnitas, assim como o domínio da simbologia algébrica padrão em geral, é certamente importante na sequência da aprendizagem matemática, especialmente em situações mais complexas, mas não é estritamente necessário para descrever as relações e generalizações que podem ser percebidas e expressas através de atividades com sequências (identificação de regularidades e padrões). É possível (e deve ser estimulado, segundo as pesquisas) o uso de símbolos personalizados, criados pelos próprios alunos inicialmente, avançando a uma simbologia mais significativa 
para toda a classe, até se chegar, eventualmente, à percepção da necessidade ou da vantagem do uso de uma simbologia mais universalizada. Compreendendo isso, o professor pode propor atividades que ajudem a desenvolver o pensamento algébrico de seus alunos, respeitando os limites cognitivos deles e viabilizando o trabalho futuro com as letras.

\section{3 Álgebra e Aritmética: contribuições recíprocas}

Demana e Leitzel (1994) defendem a ideia de que as crianças podem apresentar uma melhor compreensão de conceitos algébricos se estes forem introduzidos quando elas ainda estão trabalhando com a aritmética, ou seja, através dos números e não através de formalizações que acabam por gerar a reprodução de procedimentos, em lugar de aprendizagem efetiva. Esses pesquisadores propõem uma abordagem da aritmética embasada no uso da calculadora e na resolução de problemas, visando a preparação para os estudos de natureza algébrica.

Segundo essa proposta, antes de entrar propriamente no conteúdo algébrico, o aluno passaria por atividades "pré-algébricas", onde os conceitos aritméticos seriam reforçados, dando uma base para que desenvolva raciocínios análogos em álgebra. Os exercícios visam, por exemplo, a que o aluno reforce o entendimento e o uso da propriedade distributiva da multiplicação em relação à adição, como mostrado a seguir:

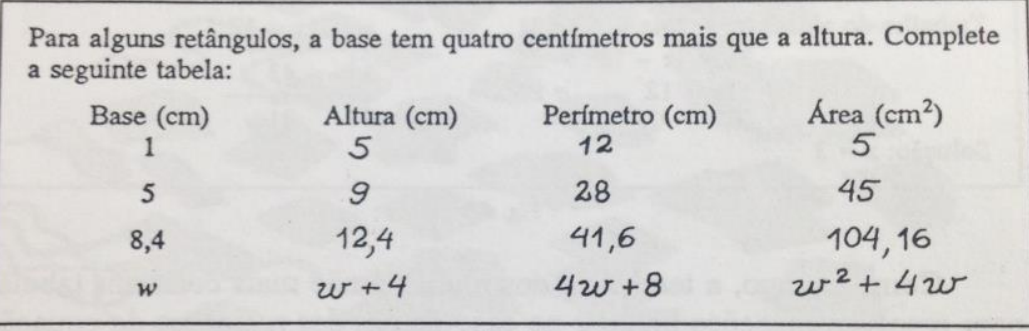

Fig. 6.2

Figura VIII. Generalizações com uso de retângulos. Demana e Leitzel,1994, p.75

Outra tarefa nessa direção seria reforçar os estudos aritméticos através do trabalho com expressões, o que valorizaria a identificação da ordem de execução 
das operações e o uso correto de parênteses, causas frequentes de dificuldades em álgebra. Esse trabalho pode ser facilitado com o uso da calculadora para ativar a percepção de que a ordem das operações pode fazer diferença no resultado final.

Uma proposta de atividade nesse sentido: solicitar aos alunos que realizem as contas correspondentes à expressão $2+5 \times 10-3 \times 4$ utilizando a calculadora, operando expressamente na ordem em que as contas são indicadas. Neste caso, obteríamos o resultado 268, pois $2+5=7 ; 7 \times 10=70 ; 70-3=67$; $67 \times 4=268$. Porém, ao fazermos o cálculo do valor da expressão na ordem correta das operações, teríamos como solução 40 , pois $2+50-12=40$. Comparar os diferentes resultados, deve levar o aluno a compreender a importância da ordem de realização das operações em uma expressão.

Trabalhar com os números negativos também é essencial para 0 desenvolvimento da capacidade de manipulação algébrica e, nessa proposta de trabalho, a calculadora desempenha, de novo, um papel importante. A atividade a seguir pode ser proposta para que 0 aluno amadureça 0 conceito de multiplicação, consiga estendê-lo de modo a fazer sentido em situações que envolvam números negativos e, também, para que desenvolva a capacidade de generalizar, o que é sempre recomendável nos estudos algébricos. A atividade consiste em solicitar aos alunos que realizem as operações para encontrar os múltiplos de determinado número, porém, ao invés de ir no sentido crescente dos inteiros, seguir o sentido decrescente. Observe:5 $54=20 ; 5 \times 3=15 ; 5 \times 2=10$; $5 \times 1=5 ; 5 \times 0=0 ; \ldots$ Pela percepção de que do lado direito da igualdade estamos sempre diminuindo 5 , à medida que diminuímos 1 no segundo fator do lado esquerdo,o aluno poderá conjecturar que o resultado da multiplicação de 5 por um número negativo deve ser negativo.Outros exemplos de atividades que podem ser trabalhadas ainda nos estudos aritméticos, mas voltadas para 0 desenvolvimento do pensamento algébrico são listadas abaixo (adaptados de Blanton, 2008). 
1. O que acontece quando adicionamos um número par a um número impar? $O$ resultado é par ou impar? Faça uma conjectura que expresse o que você acha que seja uma resposta geral. Como você pode verificar se sua conjectura é verdadeira, isto é, se vale para quaisquer números?

2. O que acontece quando adicionamos três números ímpares? O resultado é par ou ímpar? E se forem quatro números ímpares? Suponha que the fosse pedido para adicionar diversos números ímpares, mas não fosse especificado quantos. $O$ que você pode dizer sobre o resultado (em relação a ser par ou impar)? Como você poderia comprovar a veracidade de sua conjectura?

O estudo de diferentes casos particulares com a ajuda da calculadora pode aguçar o "faro" dos estudantes para o processo de generalização, já que esse instrumento potencializa a realização de testes desse tipo, de forma rápida e eficaz. Segundo relatos de experiências nesse sentido, no início a generalização se expressa verbalmente e depois avança no uso de símbolos ad hoc chegando eventualmente às letras e fórmulas da linguagem algébrica usual. Os valores testados pelos alunos podem ser escritos em tabelas e depois expressos graficamente, valorizando a visualização e a multiplicidade de formas de representação de uma dependência funcional, antes mesmo do aluno ser apresentado ao conceito de função. A introdução da noção de variável, através de situações concretas e da construção de tabelas, anteriormente ao trabalho direto com as fórmulas da linguagem algébrica padrão, é, segundo Demana e Leitzel, fundamental no desenvolvimento do pensamento funcional e, portanto, no domínio dos conceitos ligados ao estudo das funções.

Demana e Leitzel (1994), em acordo com ampla literatura que veio a se desenvolver nos anos seguintes (e comentada, em parte, neste trabalho), reforçam a ideia, já mencionada anteriormente, de que é possível introduzir aspectos do pensamento algébrico ainda no aprendizado da aritmética. Isso traz a vantagem de fortalecer e aprofundar o raciocínio aritmético dos alunos e, deste modo, assentar as bases para o domínio dos significados da simbologia e das técnicas algébricas. Tais técnicas, como se sabe, serão usadas fortemente na 
resolução de problemas, na argumentação e na aprendizagem matemática em geral, ao longo de todo o processo de formação escolar.

\subsection{O simbolismo algébrico: sintaxe e semântica}

Granell (1997) utiliza o termo sintático, para se referir às regras e manipulações algorítmicas e, de um modo geral, ao trabalho procedimental com o símbolos matemáticos; e o termo semântico para se referir aos significados dos símbolos e das operações envolvidas nas diferentes situações em estudo, à pertinência ou legitimidade da lógica subjacente às regras, aos fundamentos da validade de uma regra,em um dadocontexto. Segundo a autora, alguns alunos são "treinados" na utilização dos recursos sintáticos, tendo, aparentemente, um grau maior de destreza para resolver problemas algébricos de determinado tipo, a partir de um ponto em que se demanda apenas o domínio dos procedimentos (por exemplo, a resolução de uma equação do primeiro grau). Porém, na resolução de problemas que exigem recursos semânticos (por exemplo, a "tradução" da situação-problema da linguagem natural para a linguagem algébrica), esses mesmos alunos podem encontrar grande dificuldade, se não tiverem desenvolvido uma compreensão adequada dos significados dos símbolos algébricos.

$\mathrm{Na}$ resolução de problemas matemáticos, os alunos utilizam diferentes formas de raciocínio para compreender o contexto e a estrutura semântica da linguagem matemática que traduz a situação em exame. Assim, eles não realizam apenas operações matemáticas previamente ensinadas. $O$ aprendizado estritamente reduzido à forma sintática torna difícil (se não impossível) associar os símbolos aos significados referenciais. Por outro lado, sem os recursos sintáticos, fica difícil resolver uma inequação, por exemplo. Assim, na educação algébrica escolar é importante observar os dois aspectos, sintático e semântico.

A resolução de equações merece atenção especial dentro dos estudos algébricos na escola, devido à sua importância na matemática e em suas aplicações.As equações constituem um tema de pesquisa frequentemente revisitado, no campo da Educação Matemática. Já são abordadas, de algum 
modo, desde os primeiros anos do ensino básico, mas não da forma como são vistas no final do Ensino Fundamental e no Ensino Médio. As primeiras ideias envolvidas no trabalho com o tema referem-se a uma compreensão dos diferentes significados do sinal de igual passando pelo uso das propriedades das operações e pela percepção de relações de reversibilidade: a multiplicação seguida da divisão pelo mesmo número volta ao estado inicial, idem com a adição e a subtração etc.. $\mathrm{O}$ aluno nesse estágio de aprendizagem (normalmente no quinto ano), pode ser exposto a situações em que vai se colocar a questão de encontrar um número que multiplicado por 5 dá como resultado 15 ou achar um número que subtraído de 16 dá 9 etc. Ou ser levado a pensar em tarefas do tipo: peça a um colega que pense um número e a esse número some 12 , depois subtraia 16. Que resultado obteve? A partir do resultado, descubra o número pensado pelo colega.

Avançando em relação a esses primeiros passos, uma discussão importante a ser feita se refere ao seguinte aspecto semântico:oque significa "solução de uma equação"? Para Bernard e Cohen (1994)esse é um ponto de partida fundamental, embora muito comumente tomado como óbvio e ignorado nas aulas de matemática da escola. Segundo os autores, a partir da compreensão do que seja solução de uma equação, o aluno tem melhores condições de avançar na compreensão da lógica dos procedimentos para a resolução. Diferentes métodos de resolução podem ser, então, discutidos, alguns deles descritos brevemente a seguir.

1) Tentativa e erro (gerar uma possível resposta e avaliar). Essa técnica consiste em testar alguns valores, substituindo-os na equação e avaliando se o valor testado é efetivamente o procurado. Não sendo, refina-se a tentativa (aumentando-se ou diminuindo-se o valor testado anteriormente), sendo esse procedimento realizado sucessivamente, até que se encontre uma solução. É claro que pode ser que nunca se encontre uma solução ou que a equação tenha várias soluções e seja encontrada apenas uma, mas o exercício vale pelo trabalho de orientar uma estratégia de raciocínio,de insistir noentendimento do 
que se apresenta como o objetivo da tarefa e de incentivo ao saudável hábito de sempre conferir a resposta encontrada.

2) O método de "esconder". Essa técnica, assim como as outras, possui suas limitações, mas pode ser interessante. A proposta é trabalhar com equações simples, que permitam, com apenas um ou dois cálculos, encontrar uma solução. O método recebe este nome porque, mentalmente, se "esconde" a incógnita e se pensa na resposta. Por exemplo, na equação $12+x=15$, se "esconde" o $x$ e se pergunta: quanto devo somar a 12 para dar 15 ?

3) O método de "desfazer". Esta técnica consiste em pensar a equação como um conjunto de operações com um número desconhecido, de tal modo que para determiná-lo bastaria, em princípio, realizar as operações no sentido contrário ao que aparece na equação. Por exemplo, tomemos a equação $\frac{7(2 x-3)-5}{10}=3$. Pelo método de desfazer, repetimos os passos, mas fazendo as operações inversas e em sentido contrário: a última operação feita para encontrar o resultado 3 foi dividir por 10, então multiplicamos o 3 por 10 para achar o valor que o numerador tinha antes de dividir por 10. Agora observamos que a última conta feita para chegar ao resultado 30 foi diminuir 5 , então somamos cinco para obter 35 como o valor de $7(2 x-3)$. E assim até encontrarmos $2 x=8$ e finalmente, $x=4$.

4) O método das equações equivalentes. Essa técnica, a mais comumente usada por ser mais geral, pode ser desenvolvida de várias maneiras, dependendo do estágio, mais ou menos avançado, de familiaridade com as manipulações algébricas e com a lógica que as suporta. A ideia é transformar a equação dada em uma equação mais simples que the seja equivalente (isto é, que tenha as mesmas soluções). Um dos recursos para entender a lógica das transformações em equações equivalentes pode ser a balança de dois pratos.

Segundo Bernard e Cohen, os métodos descritos acima estão apresentados numa ordem que pode ser seguida num trabalho de iniciação às técnicas de resolução de equações. Todos eles possuem suas vantagens e limitações, o que projeta naturalmente o salto de um para o outro. 
De acordo com Simon e Stimpson (1994), o uso de diagramasajuda a compreensão de transformações equivalentes na resolução de problemas modelados por equações. Veja o exemplo abaixo

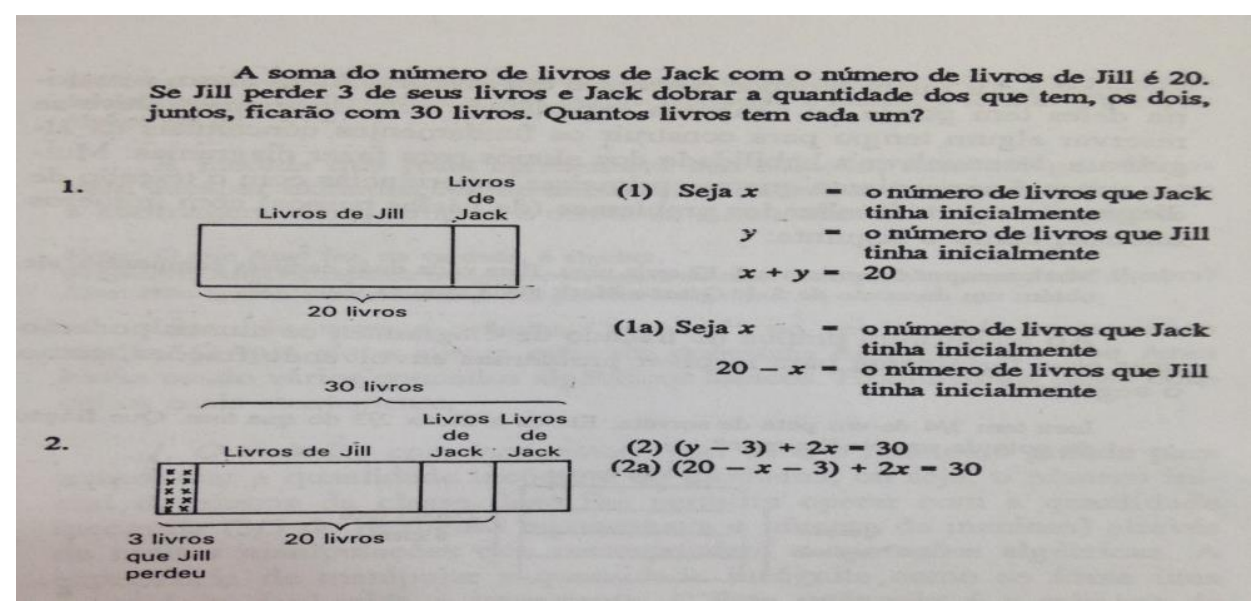

Figura IX. Diagramas para situações algébricas. Simon e Stimpson, 1994, p. 160

O diagrama torna (literalmente) visível os principais pontos do problemaa ser trabalhado. O aluno adquire uma visão concreta do que está sendo proposto, na medida em queprecisa representar o enunciado com os diagramas, ou seja, o estudante se dedica a compreender o problema antes de buscar apressadamente uma solução. Segundo os autores, uma classe iniciante em álgebra, acostumada a trabalhar com os diagramas, ao passar a utilizar as letras como incógnitas ou como variáveis percebe claramente o poder dessa linguagem algébrica mais universal, em comparação com o método dos diagramas, mas, por outro lado, o uso dos diagramas vai dar maior visibilidade ao processo de uso das letras e facilitar a sua compreensão. Desta forma, concluem Simon e Stimpson, os alunos sentem que é mais produtivo utilizar a linguagem algébrica padrão, ao mesmo tempo que compreendem o significado dos símbolos utilizados.

\section{Considerações Finais}

A álgebra está (ou deveria estar) presente em grande parte da trajetória de aprendizagem dos estudantes da Educação Básica. Desde os primeiros ciclos da escolarização é possível desenvolver o pensamento algébrico dos estudantes 
através de atividades que envolvam objetos concretos, símbolos com significados personalizados,favorecendo o futuro domínio de uma linguagem matemáticaabstrata emais adequada, em termos operacionais. As crianças podem ser levadas a pensar algebricamente através da percepção de como são formadascertas sequências de objetos, através da identificação de padrões na formação dessas sequênciase, eventualmente, daprodução degeneralizações a partir de exemplos particulares ou a partir de uma tabela construída, sempre de acordo com o estágio de maturidade cognitiva em que se encontram. Os benefícios de se levar as crianças a pensar algebricamente nos anos iniciais se refletirão em toda a formação escolar futura.

Os professores têm o importante papel de mediadores no desenvolvimento do pensamento algébrico de seus alunos e, para exercer esse papel com a qualidade devida, precisam respeitar o tempo e a maturidade cognitiva de cada aluno, mas também precisamincentivá-los com a proposição de atividades desafiadoras e adequadas a cada estágio do desenvolvimento dessa forma de pensamento matemático. Isso tudo demanda uma formação matemática qualificada (num sentido bem específico) para o professor da Educação Básica.

Ao longo dos anos escolares, os conhecimentos algébricos vão se tornando mais abstratos, inclusive porque suas relações com as situações concretas e cotidianas vão se tornando menos imediatas e menos transparentes. Assim, para dar um exemplo importante, o uso das letras para representar valores desconhecidos (fixos ou variáveis)passa a ter um papel fundamental. O bom andamento da passagem da aritmética para a álgebra dependerá, entre outros fatores, de um trabalho intensivo e permanente de desenvolvimento de uma forma específica de pensar matematicamente, ou seja, dependerá do trabalho realizado pelo professor visando desenvolver o pensamento algébrico dos seus alunos, ao longo de cada estágio da aprendizagem escolar da matemática. Os estudos mostram dificuldades dos alunos no trabalho semântico e sintático com a linguagem algébrica, ou seja, na apreensão do sentido e dosdiferentes 
significados das letras na representação de valores desconhecidos ou variáveis e, talvez até em consequência, dificuldades com simples manipulações algébricas.

É claro que esse processo de desenvolvimento do pensamento algébrico na escola, desde o reconhecimento de padrões até o estudo das funções, precisa ser mediado adequadamente pelo professor de matemática. Ao conhecerprofundamente como se desenvolve o pensamento algébrico de seus alunos, quais tipos de raciocínios são solicitados na realização de certas atividades escolares em matemática, ao familiarizar-se com os erros mais comuns cometidos pelos alunos ecom formas de superar certas dificuldades específicas do trabalho com a álgebra escolar, o professor desenvolve um perfil profissional que o torna capaz de mudarmuitas trajetórias escolares, de uma perspectiva de fracasso para uma de sucesso eventual em matemática. Esperamos que este texto,juntamente com outros trabalhos dessa natureza, venha contribuir para a ampliação do escopo de qualidade da formação docente, tanto inicial quanto em exercício, alavancando essas mudanças de trajetórias escolares ao longo da Educação Básica.

\section{Referências}

BERNARD, J. E.; COHEN, M. P. Uma integração dos métodos de resolução de equações numa sequencia evolutiva de aprendizado. In: Coxford, A.F.; Shulte, A.P. (Org.) As ideias da álgebra. São Paulo: Atual, p. 111- 126, 1994.

BLANTON, M. L. Algebra and the elementary classroom: Transforming thinking, transforming practice. Heinemann Educational Books, 2008.

DEMANA, F.; LEITZEL, J. Estabelecendo conceitos fundamentais através da resolução de problemas numéricos. In: Coxford, A.F.; Shulte, A.P. (Org.). As Ideias da Álgebra. São Paulo: Atual, p.70- 78, 1994.

GRANELL, C. G. A aquisição da linguagem matemática: símbolo e significado. In: TEBEROSKY, A.; TOLCHIRISKY, L. Além da alfabetização: a aprendizagem fonológica, ortográfica, textual e matemática. São Paulo: Ática, 1997.

KUCHEMANN, D. E. Algebra. In: HART, K. Children's understanding of mathematics. London: Murray, p.102 - 119, 1981.

PONTE, J. P.; BRANCO, N.; MATOS, A. Álgebra no ensino básico. Lisboa: DGIDC, 2009. 
http://dx.doi.org/10.5965/2357724X06102018255

RADFORD, L. Grade 2 students' non-symbolic algebraic thinking. In: CAI, J.; KNUTH, E. (Eds.). Early algebraization: a global dialogue from multiple perspectives. Berlin: Springer, p. 303-322, 2011.

SIMON, M. A; STIMPSON, V. C.; Desenvolvimento da representação algébrica através de diagramas. In: Coxford, A.F.; Shulte, A.P. (Org.). As ideias da álgebra. São Paulo: Atual, p.155- 161, 1994. 